\title{
Distributor Sharing of Strategic Information with Suppliers
}

\author{
Gary L. Frazier* \\ Elliot Maltz \\ Kersi D. Antia \\ Aric Rindfleisch
}

* Corresponding author

Gary L. Frazier is Richard and Jarda Hurd Professor of Distribution Management, Marshall School of Business, University of Southern California, HOH 803 Mail code 0443, Los Angeles CA 90089 (Ph: 213-740-5032; Fax: 213-740-7828; e-mail: frazier@marshall.usc.edu). Elliot Maltz is Professor of Marketing, Atkinson Graduate School of Management, Willamette University, 900 State Street, Salem, Oregon 97301 (Ph: 503-370-6832; Fax: 503-370-3011; email: emaltz@willamette.edu); Kersi D. Antia is Assistant Professor of Marketing, Wisconsin School of Business, University of Wisconsin-Madison, 975 University Avenue, Madison, WI 53706 (Ph: 608-263-7720; Fax: 608-265-3006; e-mail: kantia@bus.wisc.edu); Aric Rindfleisch is Professor of Marketing, School of Business, University of Wisconsin-Madison, 975 University Avenue, Madison WI 53706 (Ph: 608-262-1942; Fax: 608-265-3006; e-mail: aric@bus.wisc.edu), and Research Professor, Korea University Business School, Korea University. The authors thank the editors and reviewers for their helpful comments on earlier versions of the paper. 


\title{
Distributor Sharing of Strategic Information with Suppliers
}

\begin{abstract}
Distributor sharing of strategic information with suppliers is an important but underresearched issue within the marketing discipline. We develop and test a conceptual framework based on exchange theory that focuses on the degree to which distributors share external and internal strategic information with associated suppliers. Relying on survey data collected from 479 distributors across three industries, we find that distributors share strategic information with suppliers based on factors that impact the perceived benefits, costs, and risks of such behavior. The sharing of internal strategic information has distinct determinants compared to those of external strategic information. The inter-relationships between environmental uncertainty and the sharing of internal strategic information, involving main and interactive effects, are especially interesting.
\end{abstract}


According to marketing strategy scholars, a firm's capability to compete largely depends on its ability to obtain information about customer preferences, competitor actions, and channel member behavior (Day 1994; Kohli and Jaworski 1990; Narver and Slater 1990). The marketing channels literature echoes this sentiment and suggests that suppliers heavily rely on distributors for this information because of their direct contact with both competitors and end-customers (Coughlan, et al. 2006; Frazier 1999). Clearly, distributors possess information that is difficult, if not impossible, for suppliers to otherwise obtain.

However, distributors are often unwilling to share information with suppliers (Alderson 1965; Grabner and Rosenberg 1969). Most distributors carry products from a large number of suppliers and face resource constraints (e.g., time and opportunity costs) that hamper information sharing. In addition, the benefits of information sharing are often indirect and not clearly evident to the distributor organization (Frenzen and Nakamoto 1993). Moreover, some information may be sensitive in nature and if shared, could place the distributor organization at risk of opportunistic exploitation (Sislain and Satir 2000; Wathne and Heide 2000).

Therefore, understanding what leads distributors to share information with suppliers is important to the marketing discipline. However, this issue has received scant attention. Channel researchers have largely focused on how information sharing impacts the nature and quality of the relationship between suppliers and their distributors (Anderson and Weitz 1992; Boyle, Dwyer, Robicheaux, and Simpson 1992; Ganesan 1993; Morgan and Hunt 1994). Our research extends and enriches this prior literature by examining factors that lead distributors to share information with their suppliers. In essence, while previous work has focused on the effect of information sharing on channel relationships, our research examines the effect of channel relationships on information sharing. 
Our study centers on a particular type of information, "strategic information," which we define as processed and retained data within a distributor organization that have implications for firms' long-range decision-making (Lederer and Sethi 1996; Porter and Millar 1985). Our conceptual framework is grounded in exchange theory and enhanced by pre-study interviews among more than 20 distributors and suppliers. We consider two forms of strategic information that may be shared across organizations - external and internal. We test our conceptual framework with survey data from 479 distributors across three different industries.

Our results provide considerable support for our conceptualization and offer three key contributions. First, our research opens a new area of inquiry for marketing channels by providing an initial investigation of distributor sharing of strategic information. Thus, our research establishes a much needed conceptual and empirical baseline for the future. Second, our study enriches the marketing strategy domain by underscoring the important role that channel members play as a source of strategic information. Suppliers that utilize indirect channels need strategic information from distributors on customers, competitors, and strategic plans in order to heighten their market orientation (cf. Day 1994; Min and Mentzer 2004). Third, our research provides guidance to managers seeking access to strategic information from channel members.

\section{Strategic Information}

\section{CONCEPTUAL FRAMEWORK}

Information has been studied across a variety of disciplines and has been classified using a variety of typologies (e.g., Daft and Lengel 1986; Huber 1990; Machlup and Mansfield 1983; Nonaka 1994). Within marketing, Glazer (1991, p.2) defines information as "data that have been organized or given structure and thus endowed with meaning." In other words, information is data that have been processed and retained. 
We focus on strategic information because the collection, dissemination, and integration of market information within and across firms are primarily a strategic rather than a tactical exercise (see Nakata and Sivakumar 1996). We define strategic information as "processed and retained data within the distributor organization that have implications for firms' long-range decision-making" (Huber 1990; Porter and Millar 1985). In particular, distributors possess two important types of strategic information: external and internal. Customers and competitors exist beyond the boundaries of a distributor organization. Thus, we define external strategic information (ESI) as processed and retained data within the distributor organization about customers and competitors that have implications for firms' long-range decision making. In contrast, strategic plans are developed by top management within the distributor organization. Therefore, we define internal strategic information (ISI) as processed and retained data within the distributor organization on future plans that have implications for firms' long-range decision making. Both types of strategic information are highly valued by distributors and suppliers alike because they can enhance a firm's competitive advantage (Day 1994).

The distinctions between these two types of strategic information are important. Because ISI entails information about a distributor's future plans, it is more sensitive and proprietary in nature than ESI (Sislain and Satir 2000). Thus, from a distributor's view, there is greater potential for supplier misuse of ISI, which in turn should lead distributors to be more hesitant to share ISI compared to ESI. Furthermore, ISI is only legitimately available from top management within the distributor organization, while ESI may be obtained from other sources (Jaworski and Kohli 1993). While some common determinants will no doubt exist, we expect ISI and ESI will differ in their antecedents and consequences because of their distinct characteristics. 


\section{Theoretical Foundation}

We rely on exchange theory as the foundation for our conceptual framework because it was designed to explain resource transfers within exchange relationships (Homans 1961; Thibaut and Kelley 1959). Information has long been recognized as an important resource in exchange theory that may or may not be shared across exchange partners (Frenzen and Nakamoto 1993). Exchange theory proposes that parties, based on an evaluation of past experiences and future expectations, consider potential benefits, costs, and risks of alternative behaviors, selecting the option with the highest expected long term net benefits (Blau 1964). For a distributor, the perceived benefits of sharing strategic information are enhanced sales and margins from supplier products that better meet the needs of end-customers, as well as reciprocated rewards from grateful suppliers (Blau 1964). The perceived costs to the distributor of sharing strategic information are the time and effort associated with this activity (Blau 1964). The perceived risks to the distributor of sharing strategic information relate to the likelihood that a supplier misuses shared information to the detriment of the distributor organization (Williamson 1985).

Our conceptual framework focuses on factors likely to affect distributor perceptions of the benefits, costs, and risks of sharing ESI and ISI (see Figure 1). Based on prior research on exchange theory, we concentrate on constructs relating to the nature of the exchange relationship between distributor and supplier (Blau 1964; Frenzen and Nakamoto 1993; Homans 1961). In accordance with prior research in the marketing channels domain, we focus on interdependence, trust, and specialized investments to reflect characteristics of the exchange relationship (Anderson and Narus 1990; Frazier 1983a; Heide and John 1992). Moreover, consistent with exchange theory, we also examine a distributor characteristic, distributor 
product-market familiarity, as well as an environmental characteristic, environmental uncertainty.

\section{Research Hypotheses}

Nature of Exchange Relationship. A firm's dependence is its need to maintain a channel relationship in order to achieve desired goals (Frazier 1983b). In most channel relationships, exchange partners do not share the same degree of dependence (Kumar, et al. 1995).

Dependence asymmetry favoring the distributor reflects an exchange relationship where the supplier's dependence is higher than the distributor's dependence, providing a power advantage to the distributor organization (Emerson 1962).

Suppliers highly dependent on their distributors have a strong incentive to ensure that the channel relationship prospers over time (Buchanan 1992; Lusch and Brown 1996). Consequently, powerful distributors will likely expect that suppliers will use shared strategic information to the benefit of the distributor organization. Thus, suppliers in such relationships may utilize both ESI and ISI to enhance the attractiveness of their products to end-customers and better meet distributor needs (Day 1994). Distributor benefits should be enhanced as a result.

Furthermore, dependent suppliers are less likely to perform acts that damage their distributor (Gundlach and Cadotte 1994). In particular, a high degree of dependence makes it dangerous for a supplier to engage in opportunistic behavior or employ negative tactics because

it will have much to lose should the relationship deteriorate (Buchanan 1992; Kumar, Scheer and Steenkamp 1995). Therefore, distributors with a power advantage in a channel relationship are likely to perceive lowered risks of sharing both ESI and ISI (Jap and Anderson 2003).

\section{$\mathrm{H}_{1}$ : Dependence asymmetry favoring the distributor leads to more distributor sharing of external and internal strategic information.}


Dependence asymmetry favoring the supplier reflects an exchange relationship where the distributor's dependence is higher than the supplier's dependence. Powerful suppliers can pressure distributors to take actions that benefit their firms (Kumar, Scheer, and Steenkamp 1995). This pressure may come in the form of threatening to withhold scarce resources if distributors do not comply or, in the worst case, relationship dissolution. Further, a powerful supplier could leak sensitive strategic information to other firms (Gaski and Nevin 1985).

Thus, perceived risks of sharing ESI and ISI with powerful suppliers may be quite high, as the supplier could misuse this information to the distributor's detriment. In order to hedge against such risks, distributors may restrict strategic information sharing. In all likelihood, a powerful supplier will have difficulty ascertaining what strategic information the distributor organization actually possesses, so negative repercussions to the distributor of failing to share strategic information are likely to be low (Coughlan, et al. 2006). The potential benefits to the distributor of sharing strategic information with powerful suppliers are unlikely to offset the associated risks.

\section{$\mathrm{H}_{2}$ : Dependence asymmetry favoring the supplier leads to less distributor sharing of external and internal strategic information.}

Interdependence magnitude (IM) is the extent to which both the distributor and supplier are dependent on a channel relationship (Gundlach and Cadotte 1994). When IM is high, each firm is highly dependent on the exchange and dependence is balanced.

High interdependence magnitude reflects an exchange relationship where the distributor and supplier are each highly important to one another and on roughly equal footing. Thus, the commitment of each firm should be high (Morgan and Hunt 1994). Under such conditions, distributors are more likely to share both ESI and ISI. Balanced or symmetric dependence relationships tend to be stable and robust in nature, and less likely to dissolve over time, which 
should enhance distributor benefits (e.g., incremental sales) of sharing strategic information (Anderson and Weitz 1989; Heide 1994). Furthermore, the risks associated with information sharing should be lessened, as high interdependence makes it unlikely that the channel partners engage in opportunistic behavior since both firms have much to lose (Kumar, et al. 1995).

\section{$\mathrm{H}_{3}$ : Interdependence magnitude leads to more distributor sharing of external and internal strategic information.}

Distributor trust is the degree to which the distributor has confidence in the supplier's reliability and integrity (Morgan and Hunt 1994). Perceptions of trust are built up over time based on actions taken by the supplier that demonstrate its honesty and benevolence.

ISI is more sensitive and proprietary in nature than ESI because it entails information about a distributor's long-term plans. Furthermore, the supplier can only legitimately receive ISI from the distributor organization (Sislain and Satir 2000). As a result, the distributor is expected to be especially wary of sharing ISI relative to sharing ESI because the potential risks are high. Trust in the supplier should mitigate these perceived risks. A supplier with high reliability and integrity should be viewed by the distributor as unlikely to misuse or leak organizational plans (Frenzen and Nakamoto 1993). This type of opportunistic behavior would be incongruent with the supplier's prior efforts to demonstrate its honesty and benevolence.

\section{$\mathrm{H}_{4}$ : Distributor trust in the supplier leads to more distributor sharing of internal strategic information.}

Distributor transaction specific investments (DTSIs) are non-recoverable expenditures made by a distributor to support the sales of a supplier's products (Williamson 1985). Distributors make such investments because of the promise they hold for enhanced benefits. Because distributors have limited resources, specialized investments must be considered carefully (Buchanan 1992). Once DTSIs are made, the distributor has an incentive to protect 
them in order to reap additional benefits (Frazier 1983a; Jackson 1985). Distributor sharing of strategic information represents a form of support to the supplier organization. The supplier can use ESI and ISI to enhance its competitive offerings and better meet distributor needs, which in turn should lead to greater distributor benefits (e.g., the ease of distributor selling efforts is enhanced) (Thibaut and Kelley 1959). While there may be risks associated with sharing strategic information under such conditions (Williamson 1985), the distributor's desire to protect DTSIs and enhance potential benefits from the exchange are expected to offset these risks.

\section{$\mathrm{H}_{5}$ : Distributor transaction specific investments lead to more distributor sharing of external and internal strategic information.}

Supplier transaction specific investments (STSIs) are non-recoverable expenditures

made by a supplier to support the sales of its products by a distributor organization (Williamson 1985). They signal a supplier's good faith and willingness to do what is required to support the distributor in selling its products (Buchanan 1992; Rusbult 1980). As Anderson and Weitz (1992, p. 21) emphasize, “Observing the other party's pledges causes a channel member to be more confident in the other party's commitment to the relationship.” Thus, from a distributor's viewpoint, the risks of ESI and ISI should be attenuated, as suppliers are unlikely to jeopardize their STSIs by misusing or leaking strategic information. Furthermore, by sharing strategic information, a distributor can exhibit its own commitment to the supplier. As a result, relational functioning should improve, with enhanced benefits (e.g., reciprocated rewards) to the distributor occurring as a result (Srinivasan and Brush 2006).

\section{$\mathrm{H}_{6}$ : Supplier transaction specific investments lead to more distributor sharing of external and internal strategic information.}

A Distributor Characteristic. Distributor product-market familiarity is the extent to which a distributor understands the market for a supplier's products (Celly and Frazier 1996; 
Ozomer and Prussia 2000). Distributors with high product-market familiarity should possess a large amount of ESI to share. When the volume, depth, and accessibility of customer and competitor information is high, less time and cognitive effort is required to share such information (Alba and Hutchinson 1987; Thomas 1983). As a result, distributors with high product-market familiarity should be better able to share ESI with their suppliers.

\section{H$_{7}$ : Distributor product-market familiarity leads to more distributor sharing of external strategic information.}

An Environmental Characteristic. Environmental uncertainty (EU) is the degree to which it is difficult to make accurate predictions about the future (Achrol and Stern 1988). Two opposing viewpoints exist regarding the effect of environmental uncertainty upon exchange relationships. One view posits that when faced with high uncertainty, firms will coordinate their activities more closely in an attempt to reduce uncertainty (Pfeffer and Salancik 1978). The other view argues that firms attempt to maximize their flexibility in uncertain environments by reducing their reliance on individual relationships (cf. Heide 1994). We believe that the merit of these contrasting views varies according to the degree of sensitivity of the strategic information.

When EU is high, a distributor may perceive the sharing of ESI as an effective means of attenuating unpredictability (see Pfeffer and Salancik 1978). In particular, ESI should help suppliers interpret the meaning of changing conditions. This enhanced sense-making should improve a supplier's ability to provide the distributor with offerings that align with the shifting nature of the marketplace (Cannon and Perrault 1999). This improved alignment should benefit the distributor in terms of higher sales of the supplier's products and enhanced supplier loyalty, and thus increase its proclivity to engage in ESI sharing.

\section{$\mathrm{H}_{8 \mathrm{~A}}$ : Environmental uncertainty leads to more distributor sharing of external strategic information.}


In contrast, when EU is high, a distributor may be reluctant to share ISI because of its sensitive and proprietary nature. Suppliers could misuse ISI under such conditions. The need for safeguards is higher when EU is high (Williamson 1985). Faced with unpredictability, distributors may attempt to minimize risks and maintain flexibility in their exchange relationships by reducing resource commitments to individual suppliers (cf. Buchanan 1992; Heide 1994). Potential benefits of sharing proprietary planning information may be perceived as limited, because the future of the exchange is less predictable (cf. Achrol and Stern 1988).

\section{$H_{8 \mathrm{~B}}$ : Environmental uncertainty leads to less distributor sharing of internal strategic information.}

Moderator Effects on the Uncertainty-Sharing Relationships. High interdependence magnitude (IM) signifies that the channel relationship is essential to the goal attainment of both the distributor and the supplier. As a result, these relationships often display a high degree of stability and a real sense of "partnership" (Dwyer, Schurr, and Oh 1987; Pfeffer and Salancik 1978). An interdependent supplier should attempt to make effective use of shared external strategic information by improving the quality of its products and services to better meet the needs of an uncertain marketplace (see Pfeffer and Salancik 1978). As a result, a distributor is

likely to share even more ESI when IM is high to ensure that environmental uncertainty will not hamper the potential benefits being received from an important exchange relationship.

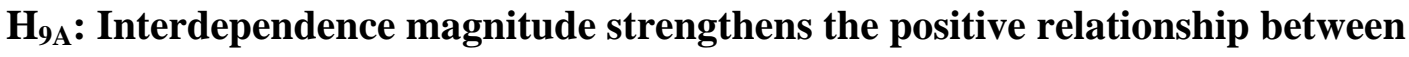 environmental uncertainty and distributor sharing of external strategic information.}

Relationships characterized by high interdependence magnitude are less likely to seriously deteriorate in highly uncertain environments, and the firms may react as partners to changing conditions. Thus, risks of supplier misuse or leaking of distributor internal strategic 
information should be reduced (Pfeffer and Salancik 1978). The safeguards to sharing ISI offered

by a high level of IM may counter-balance the tendency of distributors to reduce risk and maintain flexibility in the face of high uncertainty (cf. Ybarra and Wiersma 1999).

\section{$\mathrm{H}_{9 \mathrm{~B}}$ : Interdependence magnitude weakens the inverse relationship between environmental uncertainty and distributor sharing of internal strategic information.}

Distributor wariness to share ISI under conditions of high environmental uncertainty may also be reduced by the presence of supplier transaction specific investments. These investments serve as a signal of a supplier's intention to maintain its commitment to the channel relationship and should lessen the chances that a supplier will misuse or leak sensitive internal information (Anderson and Weitz 1992). As a result, the distributor may be less concerned about sharing proprietary internal information when uncertainty is high because the risks associated with supplier opportunism are likely to be constrained. In addition, high STSIs should motivate a distributor to share information about its plans and objectives as a means of improving inter-firm coordination and enhancing the potential benefits received from the exchange.

\section{$\mathbf{H}_{10}$ : Supplier transaction specific investments weaken the inverse relationship between environmental uncertainty and distributor sharing of internal strategic information.}

\section{RESEARCH METHOD}

Setting, Sample, and Data Collection

We tested our conceptual framework with data collected from distributors across three different industries: medical equipment (NAICS code 42145), industrial equipment (NAICS code 42183), and industrial supplies (NAICS code 42184). Pre-study interviews with more than

20 distributors and suppliers were used to ground our study. Within these interviews, we found 
that suppliers in these industries greatly value the acquisition of strategic information. We also found that distributors in these industries deal with many suppliers. Thus, for these distributors the sharing of strategic information is an important decision that entails significant costs, substantial risks, and unclear benefits. Our pre-study interviews also indicated that a distributor's principal owner or general manager is typically responsible for sharing strategic information with its suppliers. Thus, these individuals, one per distributorship, were targeted as our respondents.

We drew a random sample of 600 distributorships from Dun \& Bradstreet. The screening criteria were sales greater than $\$ 1$ million and availability of the name of the principal owner or general manager. Pre-study telephone calls were used to screen for companies that were not distributors, verify telephone numbers and mailing addresses, and ensure the contact persons were qualified respondents. After excluding distributors that could not be reached or did not qualify, our final sampling frame consisted of 501 medical equipment distributors, 506 industrial equipment distributors, and 454 industrial supplies distributors, for a total of 1,461 distributors.

We used Dillman's (2000) multi-stage survey approach to enhance our response rate. This process yielded 479 returned surveys, 150 from medical equipment distributors, 162 from industrial equipment distributors, and 167 from industrial supply distributors, for an overall response rate of $33 \%$. We compared the sales volume and geographic location for respondents versus non-respondents, and found no significant differences. We also compared first wave respondents with second wave respondents on key study constructs and found no significant differences (Armstrong and Overton 1977). Thus non-response bias appears unlikely. Measure Development 
Where possible, we employed existing measures. However, we found no suitable measures for the sharing of external and internal strategic information. Thus, we relied heavily on pre-study interviews to develop and refine measurement items. We conducted a formal pretest of the survey instrument among 60 randomly selected distributors (20 from each industry) who fit the screening criteria. A total of 17 distributors returned completed surveys. We used these responses to refine or discard items that appeared problematic. The descriptive statistics and correlation matrix for our measures are in Table 1. Unless otherwise noted, our measures were assessed using five-point Likert scales. Our final survey instrument began by asking respondents to select a product category carried by their distributorship. We then instructed them to select an important supplier in this category and keep this supplier in mind throughout the survey.

To measure distributor sharing of strategic information, we focused respondents' attention on strategic discussions during the previous year (either by phone or in person) between themselves and upper management of the supplier on issues of long-term significance. We view the sharing of external strategic information (ESI) as a higher-order construct comprising two first-order dimensions. The customer information dimension is composed of three items regarding customer feedback on major product innovations, major changes in the delivery system, and major improvements needed in product quality (alpha $=.61)$. The competitor information dimension is composed of five items focused on long-term changes in the distributor's trade area on a competitor going out of business, increased competition, product innovations by the supplier's competition, new pricing strategy by the supplier's competition, and service improvements by the supplier's competition (alpha $=.81)$.

Likewise, we view the sharing of internal strategic information (ISI) as a higher-order construct composed of two first-order dimensions. The operational planning information 
dimension consists of three items on long-term plans regarding the distributorship's inventory levels, pricing strategies, and profit margins (alpha $=.74$ ). The customer planning information dimension is composed of three items relating to long-term plans regarding the distributor's key market segment(s), new services, and important customers (alpha $=.75)$. Five-point scales ranging from 1 ("never") to 5 ("frequently") were used in measuring these items.

Our measures of dependence focus on motivational investment in goals rather than on alternatives. Following Kumar, et al. (1998), the supplier dependence measure is composed of three items that assess the importance of the distributor's trade area to the supplier, the distributor to the supplier's long term growth, and distributor contributions to the supplier's sales and profits (alpha $=.70)$. Similarly, the distributor dependence measure consists of three items that assess the supplier's contributions to the distributor's sales and profits, as well as overall importance to the distributor (alpha $=.91)$.

Dependence asymmetry is assessed by including both of these measures in the same model. In effect, the supplier (distributor) dependence measure captures the impact of a one-unit increase in supplier (distributor) dependence on information sharing, when distributor (supplier) dependence is held at the mean (Heide 1994; Marsden 1981). Hence, our supplier dependence measure reflects dependence asymmetry in the distributor's favor, while our distributor dependence measure indicate dependence asymmetry in the supplier's favor. Interdependence magnitude is derived by multiplying these two forms of dependence (Lusch and Brown 1996). High numbers reflect high and symmetric levels of each firm's dependence.

In congruence with prior research, we operationalize distributor trust as a higher order construct with two first-order dimensions. Honesty is comprised of three items drawn from Doney and Cannon (1997) that ask about the likelihood the supplier will keep its word and honor 
its commitments (alpha $=.85)$. Benevolence consists of three items that ask respondents to rate the degree to which the supplier engages in actions that support the business activities of the distributor (alpha $=.88)($ Ganesan 1993).

Our measures of distributor and supplier transaction specific investments are based on John and Weitz (1988) and Klein, Frazier, and Roth (1990). The distributor transaction specific investments measure is comprised of three items that assess the degree to which the distributor invested in facilities specific to the supplier's products, dedicated employees to the suppliers' business, and trained customers to use the supplier's products $($ alpha $=.80)$. The supplier transaction specific investments measure is comprised of three items that assess the degree to which the supplier invested in training distributor personnel, developed programs to enhance the distributor's business, and promoted ties to the distributor among end-customers (alpha $=.79$ ).

Our measure of distributor product-market familiarity is derived from Celly and Frazier (1996) and is composed of three items designed to assess the distributorship's degree of understanding of its supplier's customer requirements, awareness of changes in the productmarket, and grasp of the product-market relative to distributor competitors. The measure demonstrates acceptable internal consistency $($ alpha $=.70)$.

In congruence with John and Weitz (1988), we measured environmental uncertainty by asking respondents to evaluate the degree to which the market for the supplier's products is characterized by unpredictability and volatility. This measure consists of six items assessed with five-point semantic differential scales and displays good internal consistency (alpha $=.78)$.

Our study also includes three control variables. A distributor that carries the product lines of competing suppliers may be less inclined to share strategic information. Thus we assessed each distributor's degree of exclusive dealing by asking respondents if they carry other suppliers 
in this product category (i.e., yes or no). In addition, we control for unobserved industry-specific effects in the analysis by including two dummy variables for industry type (i.e., industrial supplies and industrial equipment).

\section{Construct Validity}

We evaluated our key measures through a series of confirmatory factor analysis models estimated via AMOS 7.0. All of our measured items could not be included in a single model without violating the five-to-one ratio of sample size to parameter estimates (Bentler and Cho 1998). Thus we specified three separate CFA models consisting of groups of theoretically similar constructs in order to provide a stringent test of discriminant validity (cf. Antia and Frazier 2001). Specifically, these three models included (1) ESI and ISI, (2) Distributor Dependence, Supplier Dependence, DTSI, STSI, and Product-Market Familiarity, and (3) Trust and Uncertainty. These models have fit indices at or above recommended standards (Model 1: $\chi^{2}=$ 239, d.f. $=72, \mathrm{GFI}=.93, \mathrm{IFI}=.93, \mathrm{RMSEA}=.07$; Model 2: $\chi^{2}=175$, d.f. $=94, \mathrm{GFI}=.96$, IFI $=$ $.97, \operatorname{RMSEA}=.04 ;$ Model $3: \chi^{2}=244$, d.f. $\left.=64, \mathrm{GFI}=.93, \mathrm{IFI}=.94, \mathrm{RMSEA}=.07\right)$. For all three higher-order construct, first- and second-order factor loadings are high (ranging from a minimum of .58 to .92$)$ and statistically significant (t-statistics ranging from 7.4 to 13.1 ).

Furthermore, each measured item has a significant $(p<.01)$ factor loading on its theorized latent construct with small and positive normalized residuals. We also conducted iterative comparative tests of one- versus two-factor solutions on pairs of the first-order constructs, and found the two-factor model to be superior to a one-factor alternative across all pairs of constructs (Bagozzi, Yi, and Phillips 1991). The Iterative Lagrange Multiplier tests provided evidence of non-significant loadings, thereby suggesting strong convergent validity. 
Collectively, these tests provide compelling evidence of the dimensionality, discriminant, and convergent validity of our measures.

\section{Assessing Potential Common Method Variance Bias}

Because our survey data were gathered from a single respondent in each distributor organization at a single point in time, our findings may be biased by common method variance (CMV). However, we believed CMV bias is unlikely given that our survey assesses constructs that are, for the most part, concrete and externally verifiable and employs highly experienced respondents (Rindfleisch, Malter, Ganesan, and Moorman 2008).

In order to assess this potential risk, we conducted three separate tests of CMV bias. First, as recommended by Podsakoff, MacKenzie, Lee, and Podsakoff (2003), we employed Harmon's one factor test. This entails entering all of the items for our latent variables into a single factor using CFA procedures. We find that the difference in the chi-squared value $\left(\chi^{2}=\right.$ $109, \mathrm{df}=40$ ) is not statistically significant. Thus, there is no general factor that accounts for the majority of the covariance across our measures, mitigating concerns of potential CMV bias.

Second, we employed the Lindell and Whitney (2001) marker variable assessment technique. In essence, this approach entails identifying a variable (i.e., marker) that is theoretically unrelated to our key constructs, assessing its smallest correlation coefficient with the study's theoretical predictors, partialling out this coefficient from the bivariate correlations, and then comparing these partialled results against the results obtained from the unadjusted correlations among the study's predictors and outcomes. We conducted this analysis using suppliers' market positioning (ranging from low end brands to high end brands) as our marker variable. This marker meets Lindell and Whitney's (2001) criterion of being theoretically unrelated to our predictor and outcome variables. After controlling for the influence of the 
marker variable via a partial correlation analysis, we find that the unadjusted correlations maintain their size and pattern of significance.

Finally, we used a variant of the marker-variable technique (Lindell and Whitney 2001) offered by Malhotra, Kim, and Patil (2006). Essentially, this technique assesses potential CMV bias by estimating and accounting for a common method-related correlation. The original correlation matrix is then adjusted for this correlation, and compared via a structural equation model against the original correlation matrix. If this comparison of adjusted versus observed correlations reveals no differences in sign or significance levels, CMV bias is unlikely.

We employed this analysis and found that the CMV-adjusted correlation matrix does not differ significantly from the uncorrected correlation matrix. Importantly, all correlations that were significant in the uncorrected correlation matrix remain significant in the CMV-adjusted matrix, and the path model yields results substantively similar to our proposed model. Collectively, the results of these three tests strongly suggest that the likelihood of CMV bias is remote, and add to the growing chorus of voices that argue that the risk of CMV bias in organizational research is considerably lower than commonly believed (e.g., Doty and Glick 1998; Malhotra et al. 2006; Rindfleisch et al. 2008).

\section{MODEL SPECIFICATION AND RESULTS}

We expected that distributor sharing of ESI and ISI would be positively though not causally related. Therefore, we employed seemingly unrelated regression (SUR) analysis to test our conceptualization. All variables involved in computing multiplicative interactions were mean-centered prior to estimation to improve the interpretability of the results.

Our omnibus results indicate that both regression models are statistically significant (ESI: $\chi^{2}=96.34, p<.001$, ISI: $\left.\chi^{2}=93.82, p<.001\right)$. The specific parameter estimates for each 
model are reported in Table 2. For the sake of reporting convenience, we indicate each ESIrelevant coefficient with the subscript "E" and each ISI-relevant coefficient with subscript "I." As shown in this table, dependence asymmetry favoring the distributor enhances the sharing of both ESI $\left(\beta_{1 \mathrm{E}}=0.13, p<.01\right)$ and ISI $\left(\beta_{1 \mathrm{I}}=0.09, p<.05\right)$. Thus, $\mathrm{H}_{1}$ is supported. However, we fail to find support for $\mathrm{H}_{2}$ and $\mathrm{H}_{3}$, as dependence asymmetry favoring the supplier and interdependence magnitude appear unrelated to the sharing of either type of strategic information $\left(\beta_{2 \mathrm{E}}=0.04, \beta_{2 \mathrm{I}}=-0.06, \beta_{3 \mathrm{E}}=-0.07, \beta_{3 \mathrm{I}}=-0.09 ;\right.$ all n.s. $)$.

Distributor trust in the supplier is positively and significantly related to the sharing of ISI $\left(\beta_{4 \mathrm{I}}=0.07, p<.05\right)$, supporting $\mathrm{H}_{4}$. Further, our results reveal that distributor transaction specific investments are positively associated with the sharing of both types of strategic information $\left(\beta_{5 \mathrm{E}}=0.19, \beta_{5 \mathrm{I}}=0.12\right.$; both $\left.p<.001\right)$. Likewise, supplier transaction specific investments are positively associated with sharing both information types $\left(\beta_{6 \mathrm{E}}=0.08, p<.01\right.$; $\left.\beta_{6 \mathrm{I}}=.13, p<.001\right)$. These results support both $\mathrm{H}_{5}$ and $\mathrm{H}_{6}$. Likewise, $\mathrm{H}_{7}$ is supported, as productmarket familiarity is positively associated with distributor sharing of $\operatorname{ESI}\left(\beta_{7 \mathrm{E}}=0.11, p<.01\right)$. Although, our results do not support $\mathrm{H}_{8 \mathrm{~A}}$, as environmental uncertainty is unrelated to ESI sharing $\left(\beta_{8 \mathrm{E}}=0.06\right.$, n.s.), they support $\mathrm{H}_{8 \mathrm{~B}}$, as environmental uncertainty is negatively related to ISI sharing $\left(\beta_{8 \mathrm{I}}=-0.12, p<.05\right)$.

The moderator hypotheses also have mixed results. Interdependence magnitude does not significantly impact the relationship between environmental uncertainty and the sharing of ESI $\left(\beta_{11 \mathrm{E}}=0.14\right.$, n.s. $)$, which fails to support $\mathrm{H}_{9 \mathrm{a}}$. However, interdependence magnitude significantly moderates the relationship between environmental uncertainty and the sharing of ISI $\left(\beta_{11 \mathrm{I}}=\right.$ $0.30, p<.05) . \mathrm{H}_{10}$ proposes a moderator effect of supplier transaction specific investments on 
the relationship between environmental uncertainty and the sharing of ISI. This moderator effect is significant as shown in Table $2\left(\beta_{12 \mathrm{I}}=0.10, p<.05\right)$.

As recommended by Aiken and West (1991), we conducted simple slope analysis to better understand the nature of our statistically significant interactions. The results of this analysis are presented in Table 3. The first portion of this table presents the main effect of uncertainty on the sharing of ISI, with the second portion focused on the moderator effect of interdependence magnitude on the relationship between environmental uncertainty and the sharing of ISI. When SDEP and DDEP are both high, the inverse association between environmental uncertainty and ISI sharing becomes non-significant, providing support for $\mathrm{H}_{9 \mathrm{~b}}$. However, the picture appears more complex than expected. Specifically, when SDEP and DDEP are both low, the inverse relationship between uncertainty and ISI sharing becomes insignificant. In contrast, when dependence asymmetry favors the distributor, the inverse relationship between environmental uncertainty and ISI is strengthened. Thus, it appears that symmetry in dependence levels attenuates, if not eliminates, the inverse relationship between uncertainty and ISI sharing, while asymmetry in dependence levels in the distributor's favor enhances this effect.

The third portion of Table 3 presents the results of the interaction of uncertainty on ISI sharing different levels of supplier transaction specific investments. At low levels of STSIs, the impact of environmental uncertainty on the sharing of ISI is negative and significant $\left(b_{\text {STSI LOW }}=\right.$ $-0.22, \mathrm{p}<.01)$. However, as STSIs increase, the inverse relation between uncertainty and ISI becomes statistically non-significant $\left(\mathrm{b}_{\mathrm{STSI} \mathrm{HIGH}}=0.02\right.$, n.s.). This pattern of results supports $\mathrm{H}_{10}$.

\section{Summary}

\section{DISCUSSION}

Our research examined the influence of a variety of relational, distributor, and environmental characteristics upon distributor sharing of two types of strategic information (i.e., 
external and internal) with upstream suppliers. We tested our conceptualization via completed surveys from nearly 500 distributors across three industries. Our results provide considerable support for our conceptualization. Specifically, we find that distributors share higher amounts of both external strategic information (ESI) and internal strategic information (ISI) with their suppliers when dependence asymmetry is in their favor and when each firm's transaction specific investments are high. Our other significant findings highlight the important theoretical distinctions that exist between ESI and ISI. In particular, environmental uncertainty has significant direct and interactive effects only upon ISI. Likewise, distributor trust facilitates the sharing of ISI, while high distributor product-market familiarity enhances sharing of ESI.

\section{Research Implications}

The flow of resources between firms has been of central interest in marketing channels research for much of its history (Coughlan, et al. 2006; Frazier 1999). Thus far, this literature has emphasized the role of inter-firm influence upon the transfer of physical resources (i.e., products) with channel systems. However, for contemporary channel relations, the flow of information between channel members to enhance organizational capabilities and decisionmaking has taken on increased importance (Dyer and Hatch 2006; Grant 1996). The acquisition of customer, competitor, and channel member information serves as the foundation of a coherent marketing strategy (Day 1994; Jaworski and Kohli 1993). Using exchange theory as our conceptual lens, our study is the first to focus on the factors that drive distributors to share strategic information with their suppliers. Thus, the results of our study provide an initial baseline of knowledge about distributor sharing of strategic information that others can build upon within the channels and marketing strategy areas of our discipline. 
Our research examines both ESI and ISI. We distinguish between these two types of strategic information on two critical dimensions: (1) the sensitivity of the information to the distributor organization and (2) the accessibility of the information to the supplier organization. ISI is by nature sensitive and proprietary (see Sislain and Satir 2000). In addition, ISI originates within the distributor organization and, unless leaks occur, its only source is distributor top management. ESI, on the other hand, is less sensitive and proprietary, as it originates outside the distributor organization. Further, suppliers can access ESI through means other than the distributor organization (e.g., supplier surveys with end-customers; industry studies by consulting firms). While our research suggests that ESI and ISI share some common determinants (i.e., interdependence and the transaction specific investments' constructs), other determinants were proposed to vary based on the unique characteristics of ESI and ISI.

We hypothesized that perceived benefits would encourage distributors to engage in greater sharing of ESI under conditions of high environmental uncertainty. Our results failed to provide support for this prediction. As predicted, however, we find that high environmental uncertainty inhibits the sharing of ISI. Under such conditions, distributors appear to lack sufficient safeguards to protect sensitive and proprietary strategic information. Because of the unpredictability of exchange relations, distributor concerns about the risks of organizational plans getting into the wrong hands are likely to be highly salient.

In a time when environmental uncertainty appears to be increasing for most firms, the inability of suppliers to attain sufficient ISI is troubling. However, our research uncovers two levers that suppliers can employ to reduce the impact of uncertainty on the sharing of ISI (i.e., interdependence magnitude and supplier transaction specific investments). First, when supplier dependence and distributor dependence are balanced or symmetric (whether at high or low 
levels), the inverse association between environmental uncertainty and ISI sharing becomes nonsignificant. As noted by Kumar et al. (1995), balanced interdependence facilitates resource exchange by promoting cooperation and discouraging opportunism. If balanced interdependence can be crafted, the adverse effects of environmental uncertainty can be attenuated.

Second, the inverse association between environmental uncertainty and ISI sharing also disappears in relationships characterized by high levels of supplier transaction specific investments (STSIs). These investments represent a credible commitment to the distributor that should reduce the perceived risks of sharing ISI in highly uncertain environments (Anderson and Weitz 1992). Although suppliers typically have more control over their specific investments than on facilitating balanced interdependence levels, scarce resources may limit the number of channel relationships in which sizeable STSIs can be made. In any case, when suppliers can put sufficient safeguards in place, high levels of environmental uncertainty should not impede distributor sharing of ISI. Thus, our research suggests that the risks posed by environmental uncertainty may be less pronounced than commonly thought (e.g., Pfeffer and Salancik 1978).

One caveat must be stressed. Our research also reveals that when dependence asymmetry favors the distributor, the inverse relationship between environmental uncertainty and ISI is strengthened. This is an intriguing finding. Apparently, the tendency to restrict ISI sharing is heightened when distributors face an uncertain environment and possess a power advantage. While the distributor is in the driver's seat in such exchange relationships, unbalanced dependence levels may create instability and a greater chance of relationship dissolution in highly uncertain environments (Kumar, et al. 1995; Pfeffer and Salancik 1978). Suppliers in such cases may simply need to face the fact they will receive less ISI from distributors than what they desire and adapt their decision-making processes accordingly. 
Two additional findings support the importance of the theoretical distinctions between ISI and ESI. First, our results indicate that distributor trust in the supplier promotes the sharing of ISI. When a supplier is seen as honest and benevolent, the distributor is likely to be reassured that its channel partner will not misuse shared ISI against distributor self-interests (Frenzen and Nakamoto 1993; Morgan and Hunt 1994). We did not expect distributor trust to impact the sharing of ESI given it is less sensitive and more accessible than ISI. Second, our results reveal distributor product-market familiarity facilitates the sharing of ESI. Not only do distributors possess a large amount of ESI when product-market familiarity is high, they also need to exert minimal cognitive effort to share such information due to its degree of depth and accessibility (Alba and Hutchinson 1987). The costs of sharing ESI appear low in such cases. Familiarity with the external environment was not expected to impact the sharing of internal plans in any way.

The importance of considering the inherent differences between ESI and ISI is highlighted by the above findings. The major research implication is that for different types of information that are shared between channel members, care must be taken in understanding the theoretical distinctions that exist among them. The antecedents and consequences of different types of information are likely to vary.

Finally, note that while our empirical analyses cannot prove causality, the opposite direction of causality in our study is much less likely. Our exchange theory orientedconceptualization and our pre-study interviews support the interpretation of the empirical results that we present. As recently argued in Rindfleisch et al. (2008), the establishment of causal inferences is largely dependent on theory rather than data. 


\section{Managerial Implications}

We believe that our research offers three key managerial implications for suppliers seeking to obtain strategic information from their distributors. First, both our theory and findings indicate that suppliers can gain higher amounts of strategic information from distributors if they are able to enhance the benefits and reduce the costs and risks that distributors perceive about engaging in this behavior. Our findings suggest that this perception management can be achieved through a variety of mechanisms, including ceding a power advantage to the distributor, undertaking investments specific to the distributor organization, encouraging transaction specific investments by the distributor, and gaining the distributor's trust. Thus, suppliers appear to have a broad variety of strategic tools that they can employ to gain access to valuable strategic information. Of course, suppliers must recognize that in some channel relationships attempts to gain significant amounts of strategic information are likely to fail. Therefore, a segmentation approach to acquiring strategic information is necessary, with suppliers seeking to gain EIS and ISI primarily in those relationships where the utilization of strategic tools is effective.

Second, suppliers need to keep careful track of how much and what type of strategic information they receive from each distributor. Without such an understanding, supplier management will have little guidance in determining what types of strategic information they need to seek from other sources and at what cost. Clearly, the acquisition of strategic information is highly important to the supplier organization, with an understanding of what is received from downstream distributors a necessary component in this process (cf. Day 1994).

Third, our findings suggest that suppliers with a power advantage in their channel relationships appear to face an important dilemma. Although the extant channels literature broadly suggests that powerful suppliers are able to gain distributor compliance (Frazier 1983b; 
Gaski and Nevin 1985), our research suggests that a supplier power advantage does little to enhance the amount of strategic information gained from distributors. Strategic information appears to be a resource that cannot be easily squeezed from downstream channel members through the use of pressure, because verifying the strategic information a distributor actually possesses is extremely difficult. Powerful suppliers may be able to partially mitigate this problem to a degree by making heavy transaction specific investments in their channel relationships and taking actions to enhance distributor trust in their organizations.

For distributors, our study identifies under what conditions distributors share ESI and ISI with their suppliers. If a distributor organization finds its sharing of strategic information varies significantly from our findings, it should re-examine the benefits, costs, and risks of this behavior. The sharing of strategic information with suppliers can provide major benefits to a distributor if costs are controlled and necessary risk-reduction safeguards are in place.

\section{Future Research Directions}

As an initial study in a new domain, our investigation represents a preliminary inquiry. Clearly, future research can extend and enrich our contributions. Thus in this final portion, we briefly identify promising directions for the future. First, future research could provide an important contribution by examining a broader array of types of information. Our inquiry examines two types of strategic information based on their degree of sensitivity and accessibility (Ghosal and Kim 1986). However, other types of strategic information no doubt exist, based on such dimensions as the degree of novelty (e.g., exploitive versus explorative) and the degree of codification (e.g., tacit versus explicit). Furthermore, the entire realm of tactical information remains untouched. Investigations into additional types of information that distributors share with upstream suppliers would nicely complement our research. 
Second, our research focused exclusively upon information sharing via traditional communication modes (i.e., telephone and face-to-face communication). However, strategic information is increasingly transmitted via electronic modes such as email and videoconferencing (Ganesan et al. 2005). Thus, future investigations could enhance our research by examining the degree to which distributors and other types of channel members are willing to transfer strategic information through both conventional and emerging modalities. Firms may be reluctant to share sensitive and proprietary information via email due to concerns about privacy and security (Vogelsang and Compaine 2000). Thus, communication modality may play an important role in determining the degree to which suppliers are able to obtain strategic information from their distributors. This role is in need of considerable elucidation in future research of information sharing activity among channel members.

Third, we presumed that the predictor variables in our conceptual framework would drive the distributor's sharing of strategic information rather than vice-versa. Given the cross-sectional nature of our data, we are unable to test this causal assumption. Future research (e.g., field experiments) aimed at examining the causal relationships between relational, environmental, and firm-based characteristics and the sharing of strategic information could be beneficial in further examining the soundness of our conceptualizaiton.

Finally, our conceptual framework largely focuses on constructs associated with the nature of the exchange relationship between distributors and suppliers. We examine only one distributor characteristics (i.e., product-market familiarity) and one environmental characteristic (i.e., environmental uncertainty). Thus, future research that examines how the sharing of strategic information is influenced by a broader array of distributor characteristics (e.g., complexity of the distributor organization; the distributor's competitive position), environmental 
characteristics (e.g., end-customer heterogeneity; supplier and distributor concentration), and supplier characteristics (e.g., desire to acquire strategic information) would be especially valuable. 
Table 1

Descriptive Statistics and Correlation Matrix

\begin{tabular}{|c|c|c|c|c|c|c|c|c|c|c|c|c|c|c|c|c|c|c|}
\hline Variable & Mean & SD & (1) & (2) & (3) & (4) & (5) & (6) & (7) & (8) & (9) & (10) & (11) & (12) & (13) & (14) & (15) & (16) \\
\hline $\begin{array}{l}\text { External Strategic } \\
\text { Information Sharing (1) } \\
\text { Internal Strategic } \\
\text { Information Sharing (2) }\end{array}$ & $\begin{array}{l}3.27 \\
3.55\end{array}$ & $\begin{array}{l}.74 \\
.74\end{array}$ & $.50 *$ & & & & & & & & & & & & & & & \\
\hline Supplier Dependence (3) & 3.65 & .80 & $.25^{*}$ & $.21^{*}$ & .70 & & & & & & & & & & & & & \\
\hline Distributor Dependence (4) & 3.30 & .50 & .07 & -.02 & $.14^{*}$ & .91 & & & & & & & & & & & & \\
\hline Distributor Familiarity (5) & 4.31 & .60 & $.24^{*}$ & $.18^{*}$ & $.33^{*}$ & .01 & .70 & & & & & & & & & & & \\
\hline Distributor Investments (6) & 3.73 & .91 & $.33^{*}$ & $.21^{*}$ & $.27 *$ & $.09^{*}$ & $.30 *$ & .80 & & & & & & & & & & \\
\hline Supplier Investments (7) & 3.14 & 1.02 & $.21 *$ & $.22 *$ & $.27^{*}$ & $.12 *$ & $.16^{*}$ & $.33 *$ & .79 & & & & & & & & & \\
\hline Trust (8) & 3.36 & .97 & -.04 & $.15^{*}$ & $.25^{*}$ & -.02 & $.10^{*}$ & -.04 & $.35^{*}$ & & & & & & & & & \\
\hline $\begin{array}{l}\text { Environmental Uncertainty } \\
\text { (9) }\end{array}$ & 2.49 & .58 & .00 & $-.16^{*}$ & $-.21 *$ & .00 & -.12 & .03 & $-.09 *$ & $-.26^{*}$ & .78 & & & & & & & \\
\hline $\begin{array}{l}\text { Supplier Inv x Uncertainty } \\
\text { (10) }\end{array}$ & - & - & -.07 & .08 & .00 & -.06 & .05 & -.05 & $-.16^{*}$ & .02 & $-.15^{*}$ & & & & & & & \\
\hline $\begin{array}{l}\text { Supplier Dep x Distributor } \\
\text { Dep (11) }\end{array}$ & - & - & -.07 & -.09 & $-.19 *$ & $-.10^{*}$ & .00 & -.04 & $-.10^{*}$ & $-.11 *$ & $.10 *$ & -.07 & & & & & & \\
\hline Supplier Dep x Uncert (12) & - & - & -.03 & -.06 & $.12 *$ & $.10^{*}$ & .03 & .00 & .00 & -.03 & -.17 & $.16^{*}$ & -.06 & & & & & \\
\hline $\begin{array}{l}\text { Distributor Dep x Uncert } \\
\text { (13) }\end{array}$ & - & - & -.02 & .04 & $.10^{*}$ & $.13^{*}$ & .01 & .01 & -.06 & .04 & $-.09 *$ & .06 & -.20 & $.11^{*}$ & & & & \\
\hline $\begin{array}{l}\text { Interdependence magnitude } \\
\text { x Uncertainty (14) }\end{array}$ & - & - & .05 & .09 & -.09 & $-.20 *$ & .05 & .07 & -.08 & -.05 & $.11 *$ & .03 & .21 & $-.34 *$ & $-.10^{*}$ & & & \\
\hline Industry Dummy 2 (15) & - & - & $.12 *$ & .05 & .05 & .05 & .02 & $.20 *$ & $.13^{*}$ & .06 & .06 & -.08 & $.12 *$ & .00 & -.02 & $-.10 *$ & & \\
\hline Industry Dummy 3 (16) & - & - & -.06 & -.03 & -.06 & -.04 & .01 & -.06 & .00 & -.03 & .05 & .01 & .08 & -.09 & .03 & $.09^{*}$ & $-.52 *$ & \\
\hline Exclusive Dealing (17) & - & - & .05 & .05 & .06 & .03 & .05 & $.22 *$ & $.12 *$ & .03 & .06 & .00 & -.00 & -.03 & .04 & .05 & $.11^{*}$ & $-.14 *$ \\
\hline
\end{tabular}

$* \mathrm{p}<.05$

Alpha values on diagonal; alphas not appropriate for second-order reflective constructs of ESI, ISI, and Trust. 
Table 2

SUR Parameter Estimates

\begin{tabular}{|c|c|c|c|c|}
\hline Predictor & & $\begin{array}{c}\text { Sharing of } \\
\text { External } \\
\text { Strategic } \\
\text { Information }\end{array}$ & & $\begin{array}{c}\text { Sharing of } \\
\text { Internal } \\
\text { Strategic } \\
\text { Information }\end{array}$ \\
\hline Intercept & $\beta_{0 \mathrm{E}}$ & $3.31(0.08)^{* * *}$ & $\beta_{0 I}$ & $3.54(0.08)^{* * *}$ \\
\hline $\begin{array}{l}\text { Dependence Asymmetry Favoring the } \\
\text { Distributor }\end{array}$ & $\beta_{1 \mathrm{E}}$ & $0.13(0.04)^{* *}$ & $\beta_{1 I}$ & $0.09(0.04)^{*}$ \\
\hline $\begin{array}{l}\text { Dependence Asymmetry Favoring the } \\
\text { Supplier }\end{array}$ & $\beta_{2 \mathrm{E}}$ & $0.04(0.06)$ & $\beta_{2 I}$ & $-0.06(0.06)$ \\
\hline Interdependence Magnitude & $\beta_{3 \mathrm{E}}$ & $-0.07(0.07)$ & $\beta_{3 \mathrm{I}}$ & $-0.09(0.08)$ \\
\hline Distributor Trust & & - & $\beta_{4 \mathrm{I}}$ & $0.07(0.03)^{*}$ \\
\hline Distributor Specialized Investments & $\beta_{5 \mathrm{E}}$ & $0.19(0.04)^{* * *}$ & $\beta_{5 \mathrm{I}}$ & $0.12(0.04)^{* * *}$ \\
\hline Supplier Specialized Investments & $\beta_{6 \mathrm{E}}$ & $0.08(0.03)^{* *}$ & $\beta_{6 I}$ & $0.13(0.04)^{* * *}$ \\
\hline Distributor Product-Market Familiarity & $\beta_{7 \mathrm{E}}$ & $0.11(0.05)^{* *}$ & & - \\
\hline Environmental Uncertainty & $\beta_{8 \mathrm{E}}$ & $0.06(0.06)$ & $\beta_{8 \mathrm{I}}$ & $-0.12(0.06)^{*}$ \\
\hline Dependence Asymmetry Favoring the & $\beta_{9 \mathrm{E}}$ & $-0.06(0.07)$ & $\beta_{9 \mathrm{I}}$ & $-0.07(0.07)$ \\
\hline Distributor x Environmental Uncertainty & & & & \\
\hline $\begin{array}{l}\text { Dependence Asymmetry Favoring the } \\
\text { Supplier x Environmental Uncertainty }\end{array}$ & $\beta_{10 \mathrm{E}}$ & $-0.07(0.11)$ & $\beta_{10 I}$ & $0.10(0.11)$ \\
\hline $\begin{array}{l}\text { Interdependence Magnitude x Environmental } \\
\text { Uncertainty }\end{array}$ & $\beta_{11 \mathrm{E}}$ & $0.14(0.14)$ & $\beta_{11 \mathrm{I}}$ & $0.30(0.14)^{*}$ \\
\hline Perceived Supplier Investments $\mathrm{x}$ & & - & $\beta_{12 \mathrm{I}}$ & $0.10(0.05)^{*}$ \\
\hline Environmental Uncertainty & & & & \\
\hline Control Variables & & & & \\
\hline Industry 2 & $\beta_{13 \mathrm{E}}$ & $0.05(0.07)$ & $\beta_{13 I}$ & $-0.02(0.08)$ \\
\hline Industry 3 & $\beta_{14 \mathrm{E}}$ & $-0.05(0.07)$ & $\beta_{14 \mathrm{I}}$ & $-0.05(0.08)$ \\
\hline Distributor Exclusive Dealing & $\beta_{15 \mathrm{E}}$ & $-0.02(0.02)$ & $\beta_{15 \mathrm{I}}$ & $-0.01(0.02)$ \\
\hline $\begin{array}{l}\text { Chi-squared Statistic (p-value) } \\
\text { Pseudo-R }\end{array}$ & \multicolumn{3}{|c|}{$\begin{array}{c}96.34(0.00) \\
0.17\end{array}$} & $\begin{array}{l}93.82(0.00) \\
0.15\end{array}$ \\
\hline
\end{tabular}

$* * * \mathrm{p}<.001, * * \mathrm{p}<.01, * \mathrm{p}<.05$, all one-tailed 
Table 3

Impact of Environmental Uncertainty on Sharing of Internal Strategic Information

\begin{tabular}{lccc}
\hline \multicolumn{1}{c}{ Type of Impact } & $\begin{array}{c}\text { Estimated } \\
\text { Impact on ISI } \\
\text { (Simple Slope) }\end{array}$ & $\begin{array}{c}\text { Standard } \\
\text { Error }\end{array}$ & t-value \\
\hline A. First-Order ("Main") Effect of EU & -.12 & .06 & $-2.00^{*}$ \\
& & & \\
\hline B. Moderator Effect of Interdependence & & & \\
Magnitude: Impact of EU on ISI at various & & & \\
levels of SDEP and DDEP & -.05 & .087 & -.57 \\
SDEP $_{\text {High }}$ and DDEP & & \\
SDEP $_{\text {High }}$ and DDEP & -.31 & .068 & -1.78 \\
SDEP $_{\text {Low }}$ and DDEP & -.18 & .101 & .36 \\
SDEP $_{\text {Low }}$ and DDEP & & \\
L. Mow $_{\text {Moderator Effect of Supplier Transaction Specific Investments: }}$ & & & \\
Impact of EU on ISI at various levels of SINV & & & \\
STSI $_{\text {Low }}$ & -.22 & .056 & $-3.1^{* *}$ \\
STSI High & .02 & .07 & .33 \\
\hline
\end{tabular}


Figure 1

Conceptual Framework

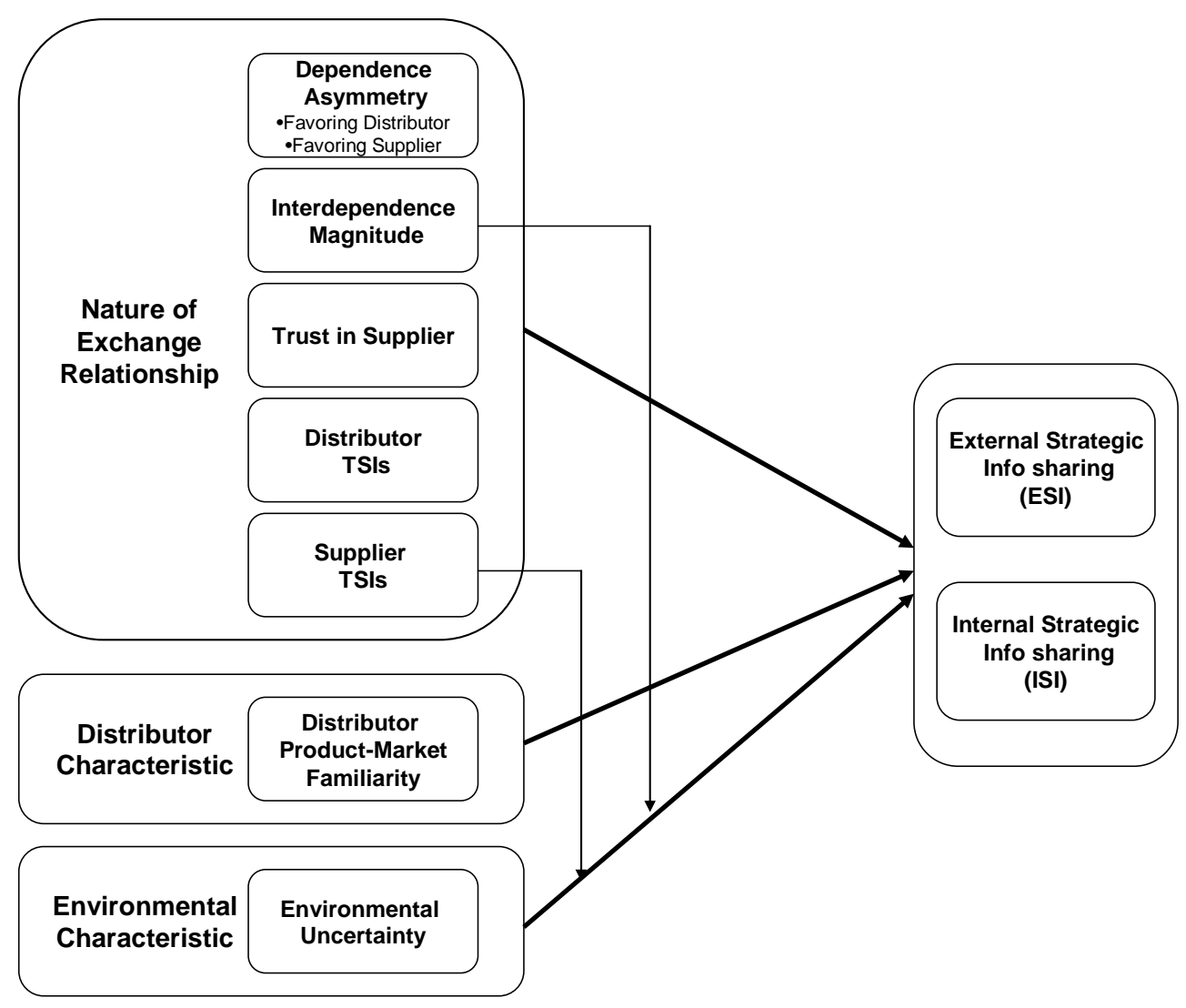




\section{REFERENCES}

Achrol, Ravi and Louis Stern (1988), "Environmental Determinants of Decision-Making Uncertainty in Marketing Channels," Journal of Marketing Research, 25 (February), 36-50.

Aiken, Leona S. and Stephen G. West (1991), Multiple Regression: Testing and Interpreting Interactions, Thousand Oaks, CA: Sage Publications.

Alba, Joseph and J. Wesley Hutchinson (1987), “Dimensions of Consumer Expertise,” Journal of Consumer Research, 13 (March), 411-54.

Alderson, Wroe (1965), Dynamic Marketing Behavior, Homewood, IL: Irwin, 239-58.

Anderson, Erin and Barton Weitz (1989), "Determinants of Continuity in Conventional Industrial Channel Dyads,” Marketing Science, 8 (Fall), 310-23.

---- and ---- (1992), "The Use of Pledges to Build and Sustain Commitment in Distribution Channels," Journal of Marketing Research, 29 (February), 18-34.

Anderson, James and James Narus (1990), "A Model of Distributor Firm and Manufacturer Firm Working Partnerships," Journal of Marketing, 54 (January), 42-58.

Antia, Kersi D. and Gary L. Frazier (2001), “The Severity of Contract Enforcement in Interfirm Channel Relationships,” Journal of Marketing, 65 (October), 67-81. 
Armstrong, J. Scott and Terry S. Overton 1977, "Estimating Non-response Bias in Mail Surveys," Journal of Marketing Research, 14 (August), 396-402.

Bagozzi, Richard, Youjae Yi, and Lynn W. Phillips (1991), “Assessing Construct Validity in Organizational Research,” Administrative Science Quarterly, 36 (September), 421-58.

Bentler, Peter and Chih-Ping Cho (1988), "Practical Issues in Structural Modeling," in Common Problems/Practical Solutions: Avoiding Error in Quantitative Research, J. Scott Long, ed., Newbury Park, CA: Sage Publications.

Blau, Peter (1964), Exchange and Power in Social Life, New York: John Wiley \& Sons Inc.

Boyle, Brett, F. Robert Dwyer, Robert Robicheaux, and James Simpson (1992), "Influence Strategies in Marketing Channels: Measures and Use in Different Relationship Structures," Journal of Marketing Research, 29 (November), 462-73.

Buchanan, Lauranne (1992), "Vertical Trade Relationships: The Role of Dependence and Symmetry in Attaining Organizational Goals," Journal of Marketing Research, 29 (February), 462-73.

Cannon, Joseph and William Perrault (1999), “Buyer-Seller Relationships in Business Markets,” Journal of Marketing Research, 36 (November), 439-60. 
Celly, Kirti and Gary L. Frazier (1996), “Outcome-based and Behavior-based Coordination Efforts in Channel Relationships,” Journal of Marketing Research, 32 (May), 200-10.

Coughlan, Anne, Erin Anderson, Louis Stern, and Adel El-Ansary (2006), Marketing Channels, $7^{\text {th }}$ edition, Upper Saddle River, NJ: Prentice-Hall.

Daft, Richard and George Lengel (1986), “Organizational Information Requirements, Media Richness, and Structural Design,” Management Science, 32 (May), 554-71.

Day, George (1994), “The Capabilities of Market-Driven Organizations,” Journal of Marketing, 58 (October), 37-52.

Dillman, Don (2000), Mail and Internet Surveys: The Tailored Design Approach, $2^{\text {nd }}$ edition, New York: John Wiley \& Sons.

Doney, Patricia and Joseph Cannon (1997), "An Examination of the Nature of Trust in Buyer-Seller Relationships," Journal of Marketing, 61 (April), 35-45.

Doty, Harold and William Glick (1998), “Common Methods Bias: Does Common Methods Variance Really Bias Results?” Organizational Research Methods, 1 (October), 374-406.

Dwyer, Robert, Paul Schurr, and Sejo Oh (1987), "Developing Buyer-Seller Relationships," Journal of Marketing, 51 (April), 11-27. 
Dyer, Jeffrey and Nile Hatch (2006), "Relation-Specific Capabilities and Barriers to Knowledge Transfers: Creating Advantage through Network Relationships," Strategic Management Journal, 27 (August), 701-19.

Emerson, Richard (1962), "Power-Dependence Relations," American Sociological Review, 27 (1), 31-41. Frazier, Gary L. (1983a), "Interorganizational Exchange Behavior in Marketing Channels: A Broadened Perspective," Journal of Marketing, 47 (Fall), 68-78.

---- (1983b), “On the Measurement of Interfirm Power in Channels of Distribution,” Journal of Marketing Research, 20 (May), 158-66.

---- (1999), "Organizing and Managing Channels of Distribution," Journal of the Academy of Marketing Science, 27 (Spring), 226-40.

Frenzen, Johnathan and Kent Nakamoto (1993), "Structure, Cooperation, and the Flow of Market Information," Journal of Consumer Research, 20 (December), 360-75.

Ganesan, Shankar (1993), "Negotiation Strategies and the Nature of Channel Relationships," Journal of Marketing Research, 30 (May), 183-203. 
----, Alan Malter, and Aric Rindfleisch (2005), "Does Distance Still Matter? The Role of Geographic Proximity in New Product Development," Journal of Marketing, 69 (October), 44-60.

Gaski, John F. and John R. Nevin (1985), “The Differential Effects of Exercised and Unexercised Power Sources in a Marketing Channel," Journal of Marketing Research, 22 (May), 130-42.

Ghoshal, Sumantra and Seok Kim (1986), "Building Effective Intelligence Systems," Sloan Management Review, 35 (Fall), 49-58.

Glazer, Rashi (1991), "Marketing in Information-Intensive Environments: Strategic Implications of Knowledge as an Asset," Journal of Marketing, 55 (October), 1-19.

Grabner, John and Larry Rosenberg (1969), "Communication in Distribution Channel Systems," in Distribution Channels: Behavioral Dimensions, Louis Stern, ed. Boston: Houghton-Mifflin Co., 227-52.

Grant, Robert (1996), “Toward a Knowledge-Based Theory of the Firm,” Strategic Management Journal, 17 (Special Issue), 109-22.

Gundlach, Gregory and Erneste Cadotte (1994), "Exchange Interdependence and Interfirm Interaction: Research in a Simulated Channel Setting," Journal of Marketing Research, 31 (November), 516-32.

Heide, Jan (1994), “Interorganizational Governance in Marketing Channels," Journal of Marketing, 58 (January), 71-85. 
---- and George John (1992), “Do norms matter in marketing relationships?” Journal of Marketing, 56 (April), 32-45.

Homans, George (1961), Social Behavior: It's Elementary Forms, New York: Harcourt, Brace and World.

Huber, George (1990), "A Theory of the Effects of Advanced Information Technologies on Organizational Design, Intelligence and Decision Making," Academy of Management Review, 15 (January), 47-71.

Jackson, Barbara (1985), Winning and Keeping Industrial Customers, Lexington, MA: Lexington Books Jap, Sandy and Erin Anderson (2003), "Safeguarding Interorganization Performance and Continuity under Ex Post Opportunism,” Management Science, 49 (12), 1684-1701.

Jaworski, Bernard J. and Ajay K. Kohli (1993), "Market Orientation: Antecedents and Consequences," Journal of Marketing, 57 (3), 53-71.

John, George and Barton Weitz (1988), "Forward Integration into Distribution: Empirical Test of Transaction Cost Analysis," Journal of Law, Economics and Organization, 4 (Fall), 121-39.

Klein, Saul, Gary L. Frazier, and Victor Roth (1990), “A Transaction Cost Analysis Model of Channel Integration in International Markets," Journal of Marketing Research, 27 (August), 196-208. 
Kohli, AjayK., and Bernard J. Jaworski (1990), "Market Orientation: The Construct, Research Propositions, and Managerial Implications," Journal of Marketing, 54 (April), 1-18.

Kumar, Nirmalya, Lisa Scheer, and Jan Benedict E.M. Steenkamp (1995), "The Effects of Perceived Interdependence on Dealer Attitudes," Journal of Marketing Research, 32 (August), 248-56.

----, ----, and ---- (1998), “Interdependence, Punitive Capability, and Reciprocation of Punitive Actions in Channel Relationships,” Journal of Marketing Research, 35 (May), 225-35.

Lederer, Albert and Vijay Sethi (1996), "Key Prescriptions for Strategic Information Systems Planning," Journal of Management Information Systems, 13 (Summer), 35-63.

Lindell, Michael K. and David J. Whitney (2001), “Accounting for Common Method Variance in Crosssectional Research Designs,” Journal of Applied Psychology, 86 (February), 114-21.

Lusch, Robert and James Brown (1996), "Interdependency, Contracting, and Relational Behavior in Marketing Channels," Journal of Marketing, 60 October, 19-38.

Machlup, F. and Una Mansfield (1983), The Study of Information: Interdisciplinary Messages, New York: Wiley and Sons. 
Malhotra, Naresh, Sung Kim, and Ashutosh Patil (2006), “Common Method Variance in IS Research: A Comparison of Alternative Approaches and a Reanalysis of Past Research," Management Science, 52 (December), 1865-83.

Marsden, Peter V. (1981), "Conditional Effects in Regression Models," in Linear Models in Social Research, P.V. Marsden, ed. Newbury Park, CA: Sage Publications, 97-116.

Min, Soonhung and John Mentzer (2004), "Developing and Measuring Supply Chain Management Concepts," Journal of Business Logistics, 25 (1), 63-99.

Morgan, Robert and Shelby Hunt (1994), "The Commitment-Trust Theory of Marketing," Journal of Marketing, 58 (July), 20-38.

Nakata, Cheryl and K. Sivakumar (1996), "National Culture and New Product Development: An Integrative Review,” Journal of Marketing, 60 (January), 61-72.

Narver, John and Stanley Slater (1990), "The Effect of a Market Orientation on Business Profitability," Journal of Marketing, 54 (October), 20-35.

Nonaka, I (1994), “A Dynamic Theory of Knowledge Creation,” Organizational Science, 5 (1), 14-37.

Ozomer, Aysegul and Gregory Prussia (2000), “Competing Perspectives in International Marketing Strategy: Contingency and Process,” Journal of International Marketing, 8 (January), 27-50. 
Pfeffer, Jeffrey and Gerald Salancik (1978), The External Control of Organizations: A Resource Dependence Perspective, New York: Harper and Row.

Porter, Michael and V. Millar (1985), “How Information Gives You Competitive Advantage," Harvard Business Review, 63 (July/August), 149-60.

Podsakoff, Philip, Scott MacKenzie, Jeong-Yeon Lee, and Nathan Podsakoff (2003), “Common Method Variance in Behavioral Research: A Critical Review of the Literature and Recommended Remedies," Journal of Applied Psychology, 88 (5), 879-903.

Rindfleisch, Aric, Alan Malter, Shankar Ganesan, and Christine Moorman (2008), “Cross-Sectional Versus Longitudinal Survey Research: Concepts, Findings, and Guidelines," Journal of Marketing Research, 45 (June), 261-79.

Rusbult, Caryl (1980), "Commitment and Satisfaction in Romantic Associations: A Test of the Investment Model," Journal of Experimental Psychology, 16 (March), 172-80.

Sislain, Eric and Ahmet Satir (2000), "Strategic Sourcing: A Framework and a Case Study," Journal of Supply Chain Management, 36 (Summer), 4-11.

Srinivasan, Raji and Thomas Brush (2006), "Supplier Performance in Vertical Alliances: The Effects of Self-Enforcing Agreements and Enforceable Contracts," Organization Science, 17 (4), 436-52. 
Thibaut, John and Harold Kelley (1959), The Social Psychology of Groups, New York, NY: Wiley.

Thomas, Ewart (1983), "Notes on Effort and Achievement-Oriented Behavior," Psychological Review, 90 (January), 1-20.

Wathne, Kenneth and Jan Heide (2000), "Opportunism in Inter-firm Relationships: Firms, Outcomes, and Solutions," Journal of Marketing, 46 (October), 36-51.

Williamson, Oliver (1985), The Economic Institution of Capitalism, New York: Free Press.

Vogelsang, Ingo and Benjamin Compaine (2000), The Internet Upheaval: Raising Questions, Seeking Answers in Communications Policy, Cambridge, MA: MIT Press.

Ybarra, Candace-Young and Margarethe Wiersma (1999), "Strategic Flexibility in Information Technology Alliances: The Influence of Transaction Cost Economics and Social Exchange Theory,” Organization Science, 10 (4), 453-59. 